Edward Crosby MD FRCPC

Department of Anaesthesia

Ottawa General Hospital

Ottawa, Ontario

\section{A mask for operations on and above the eye}

To the Editor:

Access to the airway of patients during ophthalmic surgery under topical anaesthesia is limited and may cause problems in elderly patients with respiratory and heart disease or psychological disturbance. In addition, pressure applied by the surgeon during operation makes the problem worse.

To prevent these adverse effects a new mask has been developed and has been used in ophthalmic surgery successfully for two years.

The mask is applied to the patient before preparation of the eye for surgery. The upper edge of the mask makes contact with skin at the horizontal line passes above the zygomatic arch and the nasal bridge of the patient. The lower edge of the mask makes contact with the thorax at the level of the clavicles. Then the mask is secured to the head of the patient.

The mask is made of an orthopaedic cast material called "orfix" which is malleable enough to accommodate to the face of the patient. The space between the mask and patient allows the patient to have a wide and comfortable respiration area. The surgeon does not limit the respiration of the patient unawares and also he can use the upper surface of the mask as a table for the surgical instruments.

For local operations on the eye and for the similar interventions an ideal mask has not been found. Masks used in clinical practice already can not provide the advantages described above. As a conclusion, this new mask is an invention both for the patient and the surgeon.

M. Erdal Güzeldemir
Ankara, Turkey

\section{ECT seizure classification}

To the Editor:

Until recently, it was necessary to limit the modification of electroconvulsive therapy (ECT), because if there were no visible seizure it was impossible to tell if the shock had been effective. With the advent of machines that record EEG after administering the shock, this is not mandatory. However, it is still common to permit a certain amount of muscular activity, partly because many psychiatrists prefer to see it, and partly because large doses of succinylcholine may slow recovery, which is a nuisance if there is a long list. We no longer use the isolated limb technique.

In this hospital, consecutive ECT lists are rarely done by the same anaesthetist, so it is usual to leave brief and cryptic notes for one's successor, such as, "a bit more next time". We decided to introduce some objectivity by using a score which (from our initials) we call the $\mathrm{BAD}$ score:

$0=$ No visible seizure

I = Slight twitching of the extremities

$2=$ Well-modified twitching all over

$\mathbf{3}=$ Violent movement, inadequate modification. We think this makes it easier for each anaesthetist to achieve the degree of modification desired.

William Buckingham RT (Anaesthesia Technologist)

Kent S. Anderson FRCPC (Psychiatrist)

Charles K. Davies FRCPC (Anaesthetist)

Rockyview Hospital

Calgary, Alberta

\section{Erratum}

D.C. Chung. A modified Williams airway intubator to assist fibreoptic intubation (Letter). Can J Anaesth 1998; 45: 95.

Please note that the figure printed in our January issue was not the Williams airway intubator but the LMAFasTrach $^{\mathrm{TM}}$. Below is the correct figure of the Williams airway intubator.

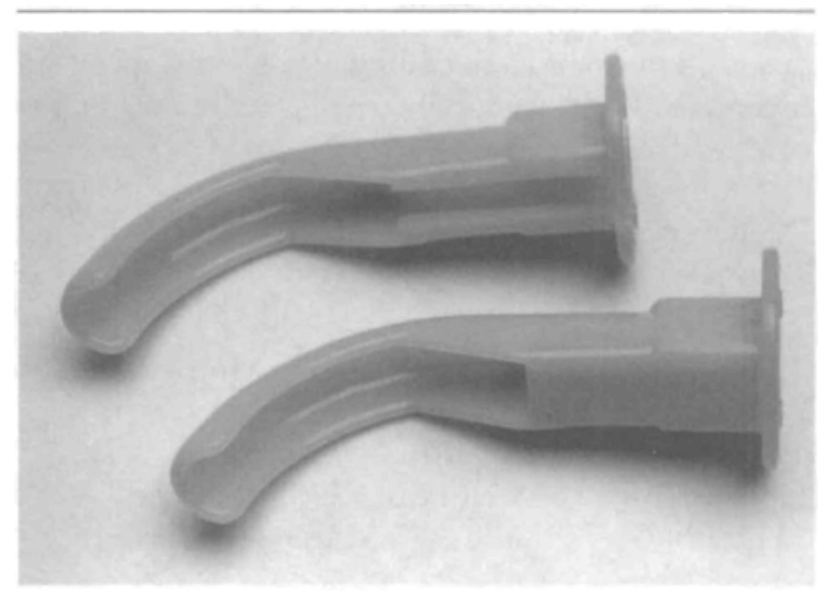

FIGURE Williams airway intubator 